\title{
Interstitial granulomatous dermatitis: a characteristic histological pattern with variable clinical manifestations
}

\author{
Izabela Błażewicz' ${ }^{1}$, Aneta Szczerkowska-Dobosz ${ }^{1}$, Rafał Pęksa², Marta Stawczyk-Macieja ${ }^{1}$, Wioletta Barańska-Rybak ${ }^{1}$, \\ Roman Nowicki ${ }^{1}$
}

\author{
'Department of Dermatology, Venereology and Allergology, Medical University of Gdansk, Gdansk, Poland \\ Head of the Department: Prof. Roman Nowicki MD, PhD \\ 2Department of Pathology, Medical University of Gdansk, Gdansk, Poland \\ Head of the Department: Prof. Wojciech Biernat MD, PhD
}

Postep Derm Alergol 2015; XXXII (6): 475-477

DOI: $10.5114 /$ pdia.2015.48060

Interstitial granulomatous dermatitis (IGD) is a distinct histopathological pattern with a diverse clinical appearance which can be associated with autoimmune systemic diseases or, rarely, with drug-related adverse reactions. The IGD is a rare entity, first described in 1993 by Ackerman, which belongs to a group of non-infectious cutaneous granulomas [1]. The disease affects mostly women, at the mean age of onset at 58 years [2]. The precise etiopathogenesis remains unknown, but the underlying inflammatory process of the dermis and granulomatous infiltrate can be involved in the development of the disease. One hypothesis suggests that the depositions of immune complexes in the dermal vessels may be the trigger, which is then followed by complement and neutrophil activation and damage of dermal collagen, which in response gives rise to a granulomatous infiltrate [3]. We present a case of IGD that seems to be a distinct entity with variable clinical manifestations, which can be easily differentiated from other granulomatous skin diseases on the basis of histopathological examination. Although the disease occurs more frequently in adults, we present a case of IGD in a child.

An 8-year-old girl was admitted for the evaluation of skin lesions of more than 2-year duration. She was initially clinically diagnosed as granuloma annulare and treated empirically with potent topical glucocorticoids without any clinical improvement. Physical examination revealed indurated, sharply demarcated, slightly erythematous, painless plaques on her right shank and single nodules on the thighs (Figure 1). She denied any systemic complaints. Family history of similar lesions and autoimmune disorders was unremarkable. No significant precipitating factors preceded skin lesions. A complete blood count, metabolic panel, C-reactive protein and rheumatoid factor were within the normal range. The titer of antinuclear antibodies was $1: 1280$. Anti-Ro, antiLa, anti-RNP and anti-Smith antibodies were negative. The histopathological examination of skin biopsy from the lesion on the right shank revealed band-like infiltrate of histiocytes in the reticular dermis with focal areas of bundles palisading around necrotic collagen (Figure 2). Based on the overall clinicopathological findings, we diagnosed interstitial granulomatous dermatitis. Due to poor results of treatment with topical corticosteroids, therapy with dapsone was implemented at a dose of $25 \mathrm{mg}$ per day (the body weight - $25 \mathrm{~kg}$ ). After 2 weeks of the treatment we observed disturbances in complete blood count: anemia and a significant increase in methemoglobin (3.5\%). The patient complained of fatigue and headache. We decided to discontinue dapsone therapy. The patient did not comply with the next follow-up visit.

The clinical presentation of IGD is heterogeneous and includes asymptomatic, multiple, erythematous to violaceus plaques with annular shape, hyperpigmented papules, nodules at different body sites $[2,4]$. The most common locations are lateral aspects of the trunk, thighs, buttocks and groin [2]. The most characteristic feature, present only in the minority of patients, is the occurrence of a thick, indurated inflammatory cord that extends from the lateral trunk to the axillae, also called the rope sign $[1,2,5]$. The lesions are asymptomatic, rarely painful or pruritic $[2,4]$. Because of a spectrum of variable clinical manifestations, a definitive diagnosis requires histological examination, which demonstrates infiltration of histiocytes in the reticular dermis with foci of degenerated collagen and interstitial infiltration of eosinophils and neutrophils [2]. The IGD can be associated with autoimmune disorders, especially systemic lupus

Address for correspondence: Izabela Błażewicz MD, Department of Dermatology, Venereology and Allergology, Medical University of Gdansk, 7 Debinki St, 80-211 Gdansk, Poland, fax: +48 7910023 15, e-mail: izabela.blazewicz@wp.pl Received: 3.05.2014, accepted: 10.10.2014. 


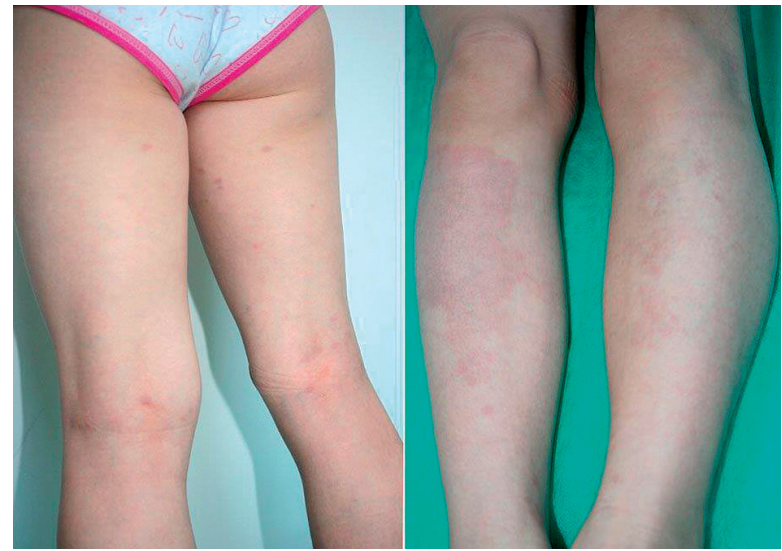

Figure 1. Erythematous, indurated, sharply demarcated plaque on the right shank and single nodules on the thighs

erythematous [6], rheumatoid arthritis [7], autoimmune thyroiditis [4], autoimmune hepatitis [8] and primary antiphospholipid syndrome [9]. Because of common coexistence of IGD and rheumatoid arthritis, a distinct entity interstitial granulomatous dermatitis with arthritis (IGDA) has been distinguished [7]. In the reported case, due to an increased titer of antinuclear antibodies and possible connection to an underlying autoimmune disorder, the

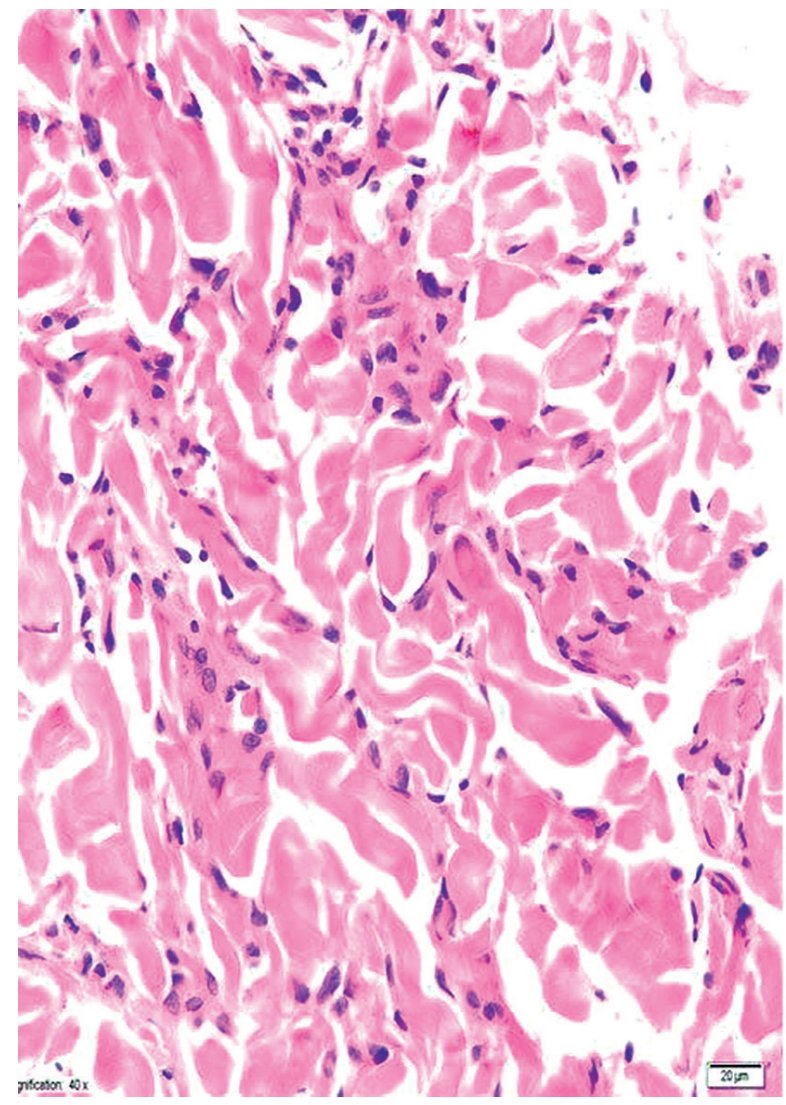

girl requires a close follow-up period. The eruption may mimic other dermatoses including granuloma annulare, erythema chronicum migrans, and the inflammatory stage of morphea. In the differential diagnosis, interstitial granulomatous drug eruption should also be taken into consideration. There are single reports suggesting onset of IGD during treatment with trastuzumab [10], tumor necrosing factor inhibitors (etanercept, adalimumab, infliximab and lenalidomide) [11], angiotensin-converting-enzyme inhibitors, lipid-lowering agents, ganciclovir [12]. Specific therapy of IGD is not well established. The first-line treatment in cases of a localized form are highpotency topical corticosteroids [4, 7]. The majority of reported IGD cases have been treated with narrow-band ultraviolet B phototherapy [7], dapsone, hydroxychloroquine [13], methotrexate [10], and oral glucocorticosteroids [2]. The relief was achieved also with ustekinumab [14], adalimumab [15] and etanercept [2]. Owing to its rarity, no therapies have been extensively studied but oral glucocorticoids seem to be the treatment of choice, especially in the case of coexistence with arthritis. According to the reports describing effective treatment with dapsone $[16,17]$ and after excluding autoimmune origin of lesions, we decided to implement dapsone therapy. Treatment of the underlying disease can also lead to re-

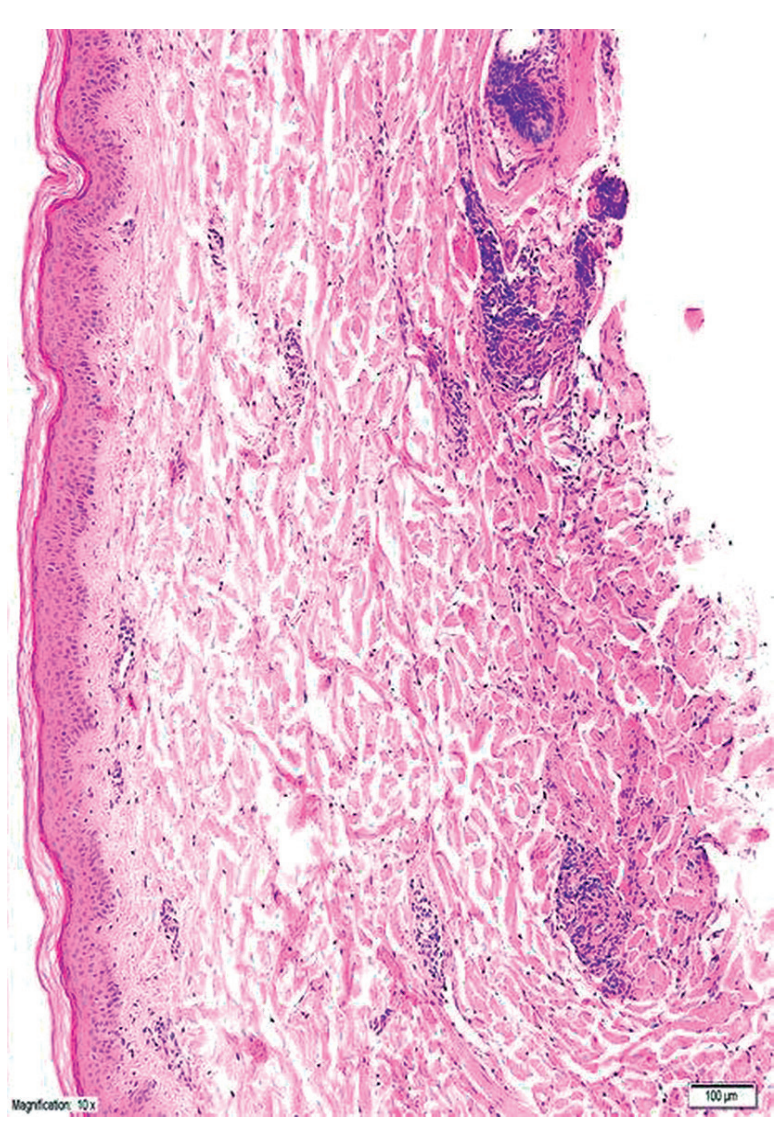

Figure 2. The histopathological examination: band-like infiltrate of histiocytes in the reticular dermis with focal areas of bundles palisading around necrotic collagen 
gression of lesions and prevent recurrences. Spontaneous resolution, periods of flares and remission and treatment resistant forms have been described [2]. Interstitial granulomatous dermatitis is underdiagnosed because of the variability of its cutaneous expression. Because of a high risk of coexistence of systemic autoimmune disorders, all patients with IGD should be closely followed up.

\section{Conflict of interest}

The authors declare no conflict of interest.

\section{References}

1. Ackerman AB. Histologic diagnosis of inflammatory skin diseases: interstitial granulomatous dermatitis with arthritis. Clues to Diagnosis in Dermatopathology. ASCP Press 1993; 309-12.

2. Peroni A, Colato C, Schena D, et al. Interstitial granulomatous dermatitis: a distinct entity with characteristic histological and clinical pattern. Br J Dermatol 2012; 166: 775-83.

3. Chu P, Connolly MK, LeBoit PE. The histopathologic spectrum of palisaded neutrophilic and granulomatous dermatitis in patients with collagen vascular disease. Arch Dermatol 1994; 130: 1278-83.

4. Antunes J, Pacheco D, Travassos AR, et al. Autoimmune thyroiditis presenting as interstitial granulomatous dermatitis. An Bras Dermatol 2012; 87: 748-51.

5. Verneuil L, Dompmartin A, Comoz F, et al. Interstitial granulomatous dermatitis with cutaneous cords and arthritis: a disorder associated with autoantibodies. J Am Acad Dermatol 2001; 45: 286-91.

6. Blaise S, Salameire D, Carpentier PH. Interstitial granulomatous dermatitis: a misdiagnosed cutaneous form of systemic lupus erythematosus? Clin Exp Dermatol 2008; 33: 712-4.

7. Jabbari A, Cheung W, Kamino H, et al. Interstitial granulomatous dermatitis with arthritis. Dermatol Online J 2009; 15: 22.

8. Lee KJ, Lee ES, Lee DY, et al. Interstitial granulomatous dermatitis associated with autoimmune hepatitis. J Eur Acad Dermatol Venereol 2007; 21: 684-5.

9. Lee HW, Chang SE, Lee MW, et al. Interstitial granulomatous dermatitis with plaques associated with antiphospholipid syndrome. Br J Dermatol 2005; 152: 814-6.

10. Martín G, Cańueto J, Santos-Briz A, et al. Interstitial granulomatous dermatitis with arthritis associated with trastuzumab. J Eur Acad Dermatol Venereol 2010; 24: 493-4.

11. Deng A, Harvey V, Sina B, et al. Interstitial granulomatous dermatitis associated with the use of tumor necrosis factor alpha inhibitors. Arch Dermatol 2006; 142: 198-202.

12. Marcollo Pini A, Kerl K. Interstitial granulomatous drug reaction following intravenous ganciclovir. Br J Dermatol 2008; 158: 1391-3.

13. Gerbing EK, Metze D, Luger TA, et al. Interstitial granulomatous dermatitis without arthritis: successful therapy with hydroxychloroquine. J Dtsch Dermatol Ges 2003; 1: 137-41.

14. Leloup P, Aubert H, Causse S. Ustekinumab therapy for severe interstitial granulomatous dermatitis with arthritis. JAMA Dermatol 2013; 149: 626-7.

15. Patsatsi A, Kyriakou A, Triantafyllidou E. Interstitial granulomatous dermatitis: another clinical variant. Case Rep Dermatol 2011; 3: 195-200.
16. He Y, Maverakis E, Ramirez-Maverakis D, et al. Combination therapy with intralesional triamcinolone and oral dapsone for management of palisaded neutrophilic and granulomatous dermatitis. Dermatol Online J 2013; 19: 17.

17. Al-Daraji WI, Coulson IH, Howat AJ. Palisaded neutrophilic and granulomatous dermatitis. Clin Exp Dermatol 2005; 30 : 578-9. 